\title{
We Have Never Been Anti-Science: Reflections on Science Wars and Post-Truth
}

\author{
MICHAEL LYNCH \\ CORNELL UNIVERSITY
}

\begin{abstract}
This essay addresses the so-called "post-truth" era in which scientific evidence of, for example, climate change, is given little weight compared to more immediate appeals to emotion and belief, and examines the relationship of alleged anti-science and populist irrationality to left- and rightwing political alignments. It also addresses charges of anti-science that were once leveled at Science and Technology Studies (STS) itself, and particularly in relation to the "symmetrical" posture taken toward scientific controversies. Recently, "symmetry" in STS has been linked to the media conventions and argumentative strategies that have sustained controversies over climate change and other health and safety concerns. This essay argues that "symmetry" was originally set up in a circumscribed way to encourage research on controversies, but that it does not amount to a general conclusion to the effect that science is no different from any other system of belief. Instead, an effort to pursue "symmetrical" research on scientific controversies can document how, far from being displaced from all relevance, scientific authority and its institutional supports are being duplicated along parallel tracks which sustain disputes and delay concerted action.
\end{abstract}

\section{Keywords}

anti-science; Trump Administration; symmetry; climate change

\section{Putting Post-truth and Anti-science in Perspective}

The treatment of science policy by the Trump administration (especially those aspects of it focused around climate change and other areas of environmental and safety policy) is part of a larger and longer-term picture that dates back at least to 1980, when Ronald Reagan was elected as President of the USA. At that time, selective government efforts to disregard and dismiss advice given by scientists and other credentialed experts was part of a larger effort to manufacture controversy in order to delay action about climate change and undermine bipartisan efforts to support and strengthen environmental policies and health and safety regulations. Reagan administration appointments, such as James Watt to head the Interior Department and

${ }^{1}$ Michael Lynch, Email: MEL27@cornell.edu 
Anne Gorsuch Burford (mother of one of Trump's appointments to the US Supreme Court) to head the Environmental Protection Agency, established a pattern that Trump expanded with his appointments of officials who set out to downsize and dismantle the agencies they were charged with administering. Cavalier treatments of science and truth also became a major concern during the G.W. Bush administration. The Trump administration's efforts to disrupt government agencies and policies concerning science, the natural environment, and health and safety, as well as a broad range of agency and sub-agency programs and regulations concerned with taxation, poverty, and many other issues, is thus not without precedent, though as Michael Lewis (2018) points out in a popular book, the current disruption extends more widely and deeply in the Federal bureaucracy than previous efforts had done.

In many media commentaries and academic discussions, the current assault on science, and more generally on technical expertise and administrative competence, has been dubbed an assault on the very concept of "truth," as part of a "post-truth" era. "Post-truth" was designated as word of the year in 2016 by the Oxford Dictionaries in connection with the Brexit and Trump campaigns. The Oxford Dictionaries defined post-truth as "[r]elating to or denoting circumstances in which objective facts are less influential in shaping public opinion than appeals to emotion and personal belief." "Post-truth" originally was coined in the 1980s in connection with the Iran-contra affair and the successful efforts by the Reagan and GWH Bush administrations to promote "plausible deniability" (Alterman 2004). It also appeared vaguely connected to academic uses of "post-modernity" to denote a contemporary episteme in which classic distinctions between truth and falsity, sense and nonsense, and objective and subjective reality were dissolving into highly flexible and politicized discourses.

"Post-truth" in governance refers not only to the thinly-disguised lying, dissembling, and obfuscating by agents in the highest echelons of government, but also to a longer-term assembly of an entire infrastructure of media organizations, consultancies and private institutes to counteract "establishment" media and science (Rampton and Stauber 2001). The contrast the Oxford Dictionaries' definition draws between "objective facts" and "appeals to emotion and personal belief" does not quite capture the challenge to science in the current era. Instead of an outright rejection of science and objectivity, what is involved is an effort to produce adversarial claims to objectivity and institutional supports for those claims. In the case of the media, the ascendency of Fox News, Breitbart, and innumerable blogs, tweets, and other sources of (mis)information has created a parallel universe to the "mainstream media" represented by The New York Times, Washington Post, and CNN. Charges of "fake news" echo across the gulf between these parallel media universes. Similarly, we find efforts to enlist scientific authority to support special creationism or climate skepticism, and to denounce Darwinian evolution or climate science as "junk science." For example, if one conducts a web search for "junk science," the most prominent site that comes up is "junkscience.com." The site is a forum for lobbyist and Fox News commentator Steven Milloy, who for more than a decade has carried on a campaign mainly against environmental science and policy. The term "junk science" also was popularized by Peter Huber (1989) of the Manhattan Institute in reference to evidence used by plaintiffs in class action lawsuits against pharmaceutical companies, manufacturers of breast implants, and other 
corporations accused of disseminating harmful products. Not surprisingly, and similar to the way "fake news" is freely invoked in accusations and counteraccusations by Trump and his critics, Milloy and Huber have themselves been accused of purveying junk science that favors the interests of their corporate sponsors.

The rejection of science by Milloy and Huber is selective, and is paired with a roughly Popperian skepticism that targets pseudoscience in favor of "genuine" science. Consequently, it is not as though there is a clear-cut division between anti-science and pro-science political factions. The leading skeptics in disputes about anthropogenic climate change do not present themselves as anti-scientists, but instead proffer their scientific credentials and argue that their skepticism is more soberly scientific than the conspiracy theories advanced by their opponents. Even in the long-term dispute in the USA about local and state legislation designed to oppose Darwinian theory and promote Fundamentalist Christian versions of creationism, proponents of the latter have increasingly couched their positions with the rhetoric of secular science ("Intelligent Design" being the latest iteration). Public confusion--either by design or inadvertent effect-is a predictable outcome when credentialed spokespersons, who themselves are accused of partisanship, accuse their opponents of anti-scientific bias.

Some commentators have responded to the sense of irresolvable and politicized controversy suggested by the idiom of "post-truth" by distinguishing between genuine controversies and artificially maintained controversies (for example, Oreskes and Conway 2011). Accordingly, manufactured controversies are efforts to disrupt settled scientific knowledge with corporately interested and well-funded efforts to engender the appearance of controversy. They do so not only with rhetorical postures that impute vested interests and "group think" to "establishment" science, but also with dedicated institutes and journals, credentialed experts, and even degree-granting higher educational institutions. "Balanced" media coverage tends to abet such efforts by giving roughly equivalent coverage to spokespersons for the opposing sides in such "scientific controversies." This sense of ongoing controversy tends to favor policies (or nonpolicies and anti-policies) that delay or reverse efforts to address the disputed problem until the controversy about it is resolved.

The media convention of granting equivalent coverage to both sides in controversies has been criticized for tacitly elevating the credibility of purveyors of manufactured controversies. Similar criticisms have been leveled at proposals in the academic field of Science \& Technology Studies (STS) to treat scientific controversy "symmetrically" and to reject "neutral" or "value-free" science in favor of politicized treatments of science. In the remainder of this essay, I address such criticisms and argue for distinguishing "symmetry" in STS from explicit or tacit support of efforts to subvert and obfuscate consensual scientific evidence with invented sciences and institutional supports for them.

\section{STS, Symmetry, and Anti-Science}

A few commentators in recent decades have blamed (or even credited) Science \& Technology Studies with having lowered scientific facts to the level of beliefs. They allege that this 
encourages an even-handed analytical treatment of all beliefs, including those that might otherwise be dismissed as conspiracy theories. Like objections to the convention in news reporting of giving "balanced" treatment of the opposing sides in (apparent) controversies, a "symmetrical" stance in STS is blamed for elevating cranks, wing-nuts, and gaslighters to equivalent epistemic standing with bona fide scientists. Though certainly not responsible for the current administration's science policy, STS has been dragged into what has been called a "war on science." Although the context and stakes are quite different, this recalls a "science war" that occurred two decades ago.

In the 1990s, a broad array of social, cultural, and feminist critiques that sought to democratize science and counteract the authority of elite science were denounced in a flurry of publications and forums for being anti-science. These criticisms and the responses to them were sometimes given the hyperbolic label "science wars." The most widely publicized maneuver occurred when a leading cultural studies journal was exposed for publishing a parodic "hoax" article authored by physicist Alan Sokal (Gross and Levitt 1994; Sokal 1996a,b; Sokal and Bricmont 1998). Sokal and some of the other critics of what they called "postmodernism" identified themselves as political leftists who were concerned that the postmodern "academic left" was inadvertently aiding right-wing efforts to obfuscate well established scientific evidence that was opposed by strong corporate, religious, and populist interests. A decade later, in an op-ed piece in the Los Angeles Times, Sokal (2007) joined forces with Chris Mooney, who had written a polemic with the title The Republican War on Science (2005), and together they linked the antiscience arguments they attributed to the "academic left" to the G.W. Bush administration's selective treatment of science advice.

"Symmetry" was originally proposed as a methodological policy by David Bloor (1976), and he and Barry Barnes, a close colleague in the Science Studies Unit at the University of Edinburgh, also used the term "equivalence postulate" in an essay promoting what they called the "Strong Programme" in the sociology of knowledge (Barnes and Bloor 1982); "strong" because it would permit no exemption from sociological explanation for even the most well-established scientific and mathematical laws, facts, and procedures. In principle, sociological research on how controversies are settled and consensus established in modern scientific and mathematical fields would deploy the same explanatory concepts (social interests, persuasion, credibility, cultural authority, etc.) as they do in explanations of alignments around cultural beliefs, religious doctrines, and political ideologies. Bloor and Barnes (1970), and Collins (1985) explicitly adopted a position of relativism (more akin to Mannheim's (1936) "relationism," than to philosophical relativism). Consensual scientific knowledge would be treated as a matter of "belief," without pre-deciding whether it is true, successful, or efficacious as judged from an enlightened standpoint. As Bloor (1976) put it, the "same types of cause would explain, say, true and false beliefs." Importantly, the salience of "social" explanations would not be precluded by the prior acceptance of a scientific theory or the establishment of a scientific fact as true. Another of Bloor's postulates was impartiality "with respect to truth and falsity, rationality and irrationality, success or failure" (Bloor 1976: 7; for recent commentaries see Sismondo 2017; Lynch 2017). Symmetry can be viewed as a strong variant of the historiographic effort to avoid a present-centered history 
that reinterprets the past in light of present-day assumptions (an inevitable prospect, perhaps, but one that can be addressed if not entirely put aside). There is a further element of the climate change and other recent subjects in dispute, which is that the manufacture of controversy appears to be a deliberate (albeit deniable) and well-funded effort to delay or defeat policies that conflict with entrenched economic, religious, and other social interests.

As originally proposed, symmetry and relativism in STS were circumscribed as part of an effort to approach diverse forms of knowledge without initially classifying particular instances as true, false, rational, irrational, successful or mistaken and doomed to failure. However, when loosely interpreted as a conclusive position about the nature of science and its relation to other modes of knowing, symmetry was easily and frequently politicized. On the one hand, it could be generalized to question the authority of an elite cadre of experts who advise and administer the production and dissemination of certified knowledge; while on the other it could be denounced for promoting speculative and fraudulent ontological claims as though they had equivalent status with well-established scientific knowledge. Although some efforts were made to make peace (e.g., Labinger and Collins 2001), and the more polarized strains of the "science wars" fizzled shortly afterwards, politicized variants of symmetry remained in play in academic STS and, increasingly, in public disputes about the political relevance and authority of consensual scientific knowledge. In what follows, I will argue that two conflations have persisted in arguments that indiscriminately treat symmetry as leverage for general arguments in science policy. One confusion has to do with the overgeneralization of symmetry, which I will briefly address in the next section. The other confusion, which I address in the section following it, arises when left-right political alignments are mapped on to a general distinction between scientific and anti-scientific ideology.

\section{Universal Symmetry?}

As I understand the "symmetry" postulate, it is a provisional stance taken at the outset of inquiry, which encourages a social historian, anthropologist, or sociologist to withhold judgment about the ultimate truth or rationality of particular knowledge claims under examination. This is not necessarily a feigned posture, taken in order to appear impartial, nor must it lead one to redowngrade the epistemic status of widely accepted scientific facts, theories, or paradigms or to upgrade the doctrines they replaced. When social historians take up controversies from centuries ago in which such phenomena as phlogiston, caloric, or spontaneous generation were eventually replaced by more modern conceptual systems, rather than dismissing them as irrational such historians can gain an understanding of why and how those now-discredited systems made sense to contemporaries and were congruent with contemporary ways of life. What does not necessarily follow from such understanding is an endorsement of those discredited systems.

In the case of disputes about climate change, few historians or social scientists are trained to conduct technical evaluations of the current models and predictions that are in dispute. Tentatively suspending judgment about the knowledge, interests, and motives of central parties to the dispute enables the analyst to delve more deeply into the reasoning and evidence mustered 
by the adversaries. Symmetry does not preclude noticing differences between the contending parties, their backgrounds, commitments, and arguments, but it does discourage using familiar, and all-too-easy, arguments to dismiss one or another position as irrational, ignorant, or dishonestly motivated. This is not so much a policy of interpretive charity as it is a strategy for gaining insight into the practical actions, discourse, and institutional supports that give rise to and sustain the resilience of such public controversies.

One point about symmetry, as Bloor originally set out the postulate, is that, contrary to Fuller's (2016) advocacy of a "symmetry principle universalized," it does not purport to be a "post-truth" that applies in the same way in all cases. Far from appealing "to emotion and personal belief," parties on both sides of current environmental controversies make strong factual claims, sometimes qualified by degrees of uncertainty, and as mentioned earlier they typically claim scientific authority. Even in the series of disputes in the US courts about teaching creationism in public schools, both sides claim scientific authority, though one side has never succeeded in demonstrating to the satisfaction of the federal courts that their scientific claims are anything other than thinly veiled religious arguments. If anything, so-called "post-truth" politics is more a matter of duplicating the appearance rather than erasing the relevance of objective truth. Both sides present truth claims backed by the authority of "science" and supported with institutes, bodies of literature, museums, and other institutions. Pursuing research guided by the symmetry postulate may not provide clear guidance for demarcating which sciences and scientific claims are real and which are fake, though detailed research in particular cases may be sufficient to reach pragmatic judgments on such matters. However, symmetry does encourage a sustained effort to document the sources of resilience that sustain controversies, and that is valuable in its own right.

\section{Anti-Science and Left-Right Politics}

The politics of pro-/anti-science also cannot be easily demarcated along a left-right dimension (Latour 2018). Currently, in the USA climate skepticism is entrenched on the right, and concern about climate change, mass extinction, and other aspects of the current environmental crisis are strongly aligned with the left. However, despite the general anti-science label attributed to the political right, and particularly the Republican Party in the USA (Mooney 2005), when we examine a broader range of issues, it becomes apparent that it is not as though public support for allegedly scientific or anti-scientific positions always aligns along a left-right axis. Instead, such alignment varies with the particular issues and interests at stake. Consider the campaigns that are often branded as anti-scientific: anti-vaccination campaigns, opposition to genetically modified foods, climate skepticism, efforts to embed creationism and intelligent design in public schools, and support for embryonic personhood. These social movements sometimes attract politically left-leaning or right-leaning constituencies, and sometimes both or neither. It is also the case that, as mentioned earlier, all sides in such debates tend to invoke scientific authority, though in some cases the authority invoked is widely discredited, such as in the case of the thesis by Andrew Wakefield that the Mumps, Measles, and Rubella (MMR) vaccine was linked to autism. The long 
history of campaigns against fluoridation in public drinking water exhibits an occasional coalition of right (libertarian, anti-socialist) and left (environmentalist) political factions, dating back to the 1940s (Mazur 1981).

A similar point holds for expertise. There is a long-standing concern about expert authority in a democratic society. A stark variant of the problem arises in trial courts in an adversary system, where the opposing sides enlist credentialed forensic, medical and/or academic witnesses to support their legal arguments and counter-arguments. The problem is that jurors and judges charged with making decisions are likely to be confused by such opposing technical claims. This is by no means a new problem (Hand 1901). As a practical matter, "lay" decision makers (not unlike many credentialed decision makers) rely upon "proxies" to assess the credibility of particular experts and their claims (Shapin 1995). Proxies are common-sense criteria such as the numbers of proponents on each side, the relevance of their specialized knowledge to the dispute at hand, their institutional credentials, their reputations for disinterested truth-telling, the demeanor with which they convey their testimony, and other aspects of their social esteem and status. Perhaps the most often-cited (and frequently contested) proxy in support of the thesis of anthropogenic climate change is the $97 \%$ consensus among climate scientists. Like the anti-science charge, the complaint that "populist" movements nowadays are rejecting expertise tends to be undiscriminating. The complaint is not completely wrong, but it tends to suppose that the dismissal of particular experts who apparently threaten strongly held interests, commitments, and habits is an across-the-board rejection of all expert advice.

\section{Conclusion}

In this essay, I suggested that the impression that many of us now have of a systematic opposition to science, expertise, and facts by Trump, many in his cabinet, his media backers, his wealthy supporters, and his vociferous base is perhaps more acute than we have seen in the recent past, but is far from novel. Moreover, I suggested that it may be less helpful to speak of an anti-science campaign or "post-truth" era, than to treat it as a more selective opposition to or denial of modes of inquiry and specific facts (whether associated with scientific investigations or more widely available understandings and observations) that threaten (or are believed to threaten) entrenched economic interests, religious beliefs and political doctrines, and collective habits. Such opposition is often expressed through the rhetoric of science, voiced by credentialed experts who present counter-narratives and "alternative facts." Far from being an opposition to "science," it makes selective use of emblems and idioms of scientific authority. Perhaps the problem is not anti-science per se, but the collapse of more nuanced debate into over-generalized "scientific" claims in the public airing of disagreements.

Many of us who would defend climate science against skeptical attacks and dismissals, might also find ourselves skeptical about other alleged instances of official scientific consensus; for example, about the safety of genetically modified foods. Neither position is a defense or rejection of science in general. Moreover, these debates are not only about what is or is not 
scientifically established. In the case of debates about GM foods, it is all too easy to forget that there are broad "matters of concern" (Latour 2004) about the means and consequences of food production besides scientifically (and Food and Drug Administration) attested facts. With regard to climate change, the main political problem at the moment in the USA is not "anti-science" but the relatively low political salience of the topic. Despite the urgent emphasis in reports and public statements by the Intergovernmental Panel on Climate Change (IPCC) and other scientific organizations, climate policy remains a secondary or even peripheral issue, even for the current majority of the American public that registers general support for it in polls (though, very recently, there does seem to be increased public concern). The challenge for those of us in STS who are convinced that climate change should be of overwhelming political concern is to assist in raising its salience without reverting to the uncritical and overgeneralized invocation of "science" that currently characterizes the debate.

\section{Author Biography}

Michael Lynch is Professor Emeritus in the Department of Science \& Technology Studies, Cornell University.

\section{References}

Alterman E. 2004. When Presidents Lie: A History of Official Deception and Its Consequences. New York: Viking.

Barnes, B. and D. Bloor. 1982. Relativism, Rationalism, and the Sociology of Knowledge. In M. Hollis and S. Lukes, eds., Rationality and Relativism. Cambridge, MA: MIT Press.

Bloor, D. 1976. Knowledge and Social Imagery. London: Routledge and Kegan Paul.

Collins, H.M. 1985. Changing Order: Replication and Induction in Scientific Practice. London and Beverly Hills: Sage.

Fuller S. 2016. Embrace the Inner Fox: Post-Truth as the STS Symmetry Principle Universalized. Social Epistemology Review \& Reply Collective. Available at: https://socialepistemology.com/2016/12/25/embrace-the-inner-fox-post-truth-as-the-sts-symmetryprinciple-universalized-steve-fuller/\# comments.

Gross, P., and N. Levitt. 1994. Higher Superstition. Baltimore, MD: Johns Hopkins University Press.

Gross, P., N. Levitt, and M. Lewis, eds. 1996. The Flight from Science and Reason. New York: New York Academy of Sciences.

Hand, L. 1901. “Considerations Regarding Expert Testimony." Harvard Law Review 15: 40-58

Huber, P. 1991. Galileo's Revenge: Junk Science in the Courtroom. NY: Basic Books.

Latour, B. 2004. "Why Has Critique Run Out of Steam? From Matters of Fact to Matters of Concern." Critical Inquiry 30: 225-248.

Latour, B. 2018. Down to Earth: Politics in the New Climactic Regime. Cambridge: Polity.

Lewis, M. 2018. The Fifth Risk. NY: W.W. Norton. 
Lynch, M. 2017. STS, Symmetry and Post-Truth. Social Studies of Science 47(4): 593-599.

Mannheim, K. 1936. Ideology and Utopia. New York: Harvest Books

Mazur, A. 1981. The Dynamics of Technical Controversy. Washington, D.C.: Communications Press. Mooney, C. 2005. The Republican War on Science. NY: Basic Books.

Mooney, C., and A. Sokal. 2007. Taking the Spin Out of Science. Los Angeles Times. February 4. https: / / www.latimes.com/archives/la-xpm-2007-feb-04-op-mooney4-story.html /

New York Times. 2017. President Trump's War on Science. Editorial, Sept. 9. Available at: https: / / www.nytimes.com/2017/09/09/opinion/sunday/trump-epa-pruittscience.html?emc=edit_th $20170910 \&$ nl=todaysheadlines\&nlid=38446981

Oreskes, N., and E.M. Conway (2011) Merchants of Doubt: How a Handful of Scientists Obscured the Truth on Issues from Tobacco Smoke to Global Warming. New York: Bloomsbury.

Rampton, S., and J. Stauber. 2001. Trust Us, We're Experts: How Industry Manipulates Science and Gambles with Your Future. New York: Tarcher/Putnam.

Shapin, S. 1992. "Cordelia's Love: Credibility and the Social Studies of Science. Perspectives on Science 3(3): 235-273.

Sismondo, S. 2017. "Post-truth?" Social Studies of Science 47(1): 3-6.

Sokal, A. 1996. Transgressing the Boundaries: Toward a Transformative Hermeneutics of Quantum Gravity. Social Text 14: 217-252.

Sokal, A. 1996. Transgressing the boundaries: An afterward. Philosophy \& Literature 20(2): 338346.

Sokal, A., and J. Bricmont. 1998. Intellectual Impostures. London: Profile. 